\title{
PRATICANDO SABERES \\ E CONSTRUINDO IDEIAS \\ EM GEOCIÊNCIAS
}

\section{PRACTICING KNOWLEDGE AND BUILDING IDEAS ON GEOSCIENCE}

\author{
Cristiane Heredia Gomes* \\ Rafael Lima Dessart** \\ Diogo Gabriel Sperandio ${ }^{* * *}$ \\ Juliana Gimenes de Oliveira**** \\ Issacar Barroso $0^{* * * * *}$ \\ Caio Felipe de Oliveira Xavier ${ }^{* * * * *}$ \\ Catarine do Carmo Antunes*******
}

\section{RESUMO}

Este trabalho objetiva apresentar a formação e atuação do Projeto de Extensão Universitária “Museu Virtual Geológico do Pampa" (Sippee n0301315-UNIPAMPA), criado a partir do ideal de difundir o conhecimento geológico nas escolas da cidade de Caçapava do Sul - RS, e relatar as experiências e sentimentos oriundos dos participantes das atividades. Através da materialização de estruturas e acontecimentos geológicos, que envolvem não só o que aconteceu na região, mas episódios relacionados a todo o planeta Terra, foram realizadas pesquisas bibliográficas e oficinas. Para tanto, desenvolveram-se conversas informais, atividades práticas e registros fotográficos. Os dados obtidos indicaram que as atividades desenvolvidas no âmbito do Projeto despertaram sentimentos, sensações, interatividade, comunicação e interesse pela Geologia, implantando uma cultura geológica na comunidade local e demonstrando a importância da região no âmbito das Geociências. Percebeu-se que o aprendizado fora dos muros da escola, o contato dos alunos com o meio universitário são importantes ferramentas na educação e inclusão social.

Palavras-Chave: geologia; ensino; inclusão social; escola; extensão.

\footnotetext{
* Professora da Universidade Federal do Pampa (UNIPAMPA), RS - Brasil. E-mail: cristianegomes@unipampa.edu.br

** Professor da Universidade Federal do Pampa (UNIPAMPA), RS - Brasil. E-mail: rldessart@gmail.com

*** Aluno de graduação da Universidade Federal do Pampa (UNIPAMPA), RS - Brasil. E-mail: sperandio.gabriel@hotmail.com

**** Aluna de graduação da Universidade Federal do Pampa (UNIPAMPA), RS - Brasil. E-mail: juliana.gimenes.oliveira@gmail.com

***** Aluno de graduação da Universidade Federal do Pampa (UNIPAMPA), RS - Brasil. E-mail: issacarbarroso@hotmail.com

****** Aluno de graduação da Universidade Federal do Pampa (UNIPAMPA), RS - Brasil. E-mail: caiofelipe.ox@hotmail.com

******* Aluna de graduação da Universidade Federal do Pampa (UNIPAMPA), RS - Brasil. E-mail: catarine.antunes@hotmail.com
} 


\section{ABSTRACT}

This study aims to present the outreach project Museu Virtual Geológico do Pampa (Virtual Geological Museum of Pampa - Sippee no 0301315 - UNIPAMPA) conceived to spread knowledge about geology in schools of Caçapava do Sul - RS - Brazil. It also aims to report the experiences and feelings of the participants that took part in the activities. Through the materialization of structures and geological events, involving not only what happened in the region but also in the planet, it carried out researches and workshops. Therefore, there were informal conversations, practical activities and photographic records. The data indicated that the activities aroused feelings, sensations, interactivity, communication and interest in Geology, implementing the geological culture in the local community as well as demonstrating the importance of the region for geosciences. It was noticed that the learning conducted outside school, in which students are involved with the university environment, is an important tool for education and social inclusion.

Keywords: geology; teaching; social inclusion; school; outreach.

\section{Introduçáo}

A cidade de Caçapava do Sul - RS foi considerada recentemente como a capital gaúcha da Geodiversidade ${ }^{1}$. Na região é possível observar sua vasta diversidade geológica, a qual é representada pelos três grandes grupos de rochas (vulcânicas, sedimentares e metamórficas), suas estruturas e mineralizaçóes associadas, impressas durante 2 bilhôes de anos de evolução. Isto faz com que seja alvo de estudos no âmbito das Ciências Exatas e da Terra, e também campo para atuação de empresas de mineração vinculadas à extração de recursos minerais.

Borba (2015) destaca a diversidade geológica do município, explanando sobre evidências de fundos oceânicos e mares tropicais de idades muito antigas, diferentes tipos e composiçóes de erupçóes vulcânicas, "granitos cristalizados nas profundezas da Terra, e rios cascalhosos de grande energia que corriam em um grande deserto dos primórdios do supercontinente Gondwana [...]" (BORBA, 2015, p. 405). O mesmo autor ainda disserta sobre processos geológicos mais recentes, isto é, os geomorfológicos, sobre a beleza das formas de relevo e as paisagens de Caçapava do Sul. "As Guaritas e a Serra do Segredo são evidências claras das variaçóes climáticas dos últimos milhares de anos: climas úmidos e climas secos sucederam-se, acompanhando os períodos glaciais e interglaciais do continente sul-americano" (Idem).

Com o intuito de conscientizar as novas gerações e promover a divulgação de nossa instituição, a Universidade Federal do Pampa-Campus Caçapava do Sul, como um veículo construtor de conhecimentos científicos e culturais, foi desenvolvido o presente estudo na forma de atividades lúdicas. Neste sentido, o Projeto "Museu Virtual Geológico do Pampa" é levado às escolas do município. Através da manipulação de materiais alternativos, os alunos de diferentes idades, desde o ensino fundamental ao ensino médio, criam e aprendem sobre diferentes aspectos da formação do planeta Terra.

Além disso, o Projeto é divulgado através de um site com imagens referentes aos diferentes tipos litológicos de várias regiōes do Brasil, Europa e América Central, disponíveis no acervo da Universidade (Campus Caçapava do Sul), junto com informaçōes detalhadas e disponíveis ao usuário. O Museu desenvolve um processo de análise e tratamento das imagens disponibilizadas, tendo como alvo o uso da imagem como documento histórico portador de informaçôes que permitam a busca pelo conhecimento e, ainda, a compreensão teórico-didática aos discentes e docentes das comunidades externas e internas. $\mathrm{O}$ usuário é convidado a realizar um passeio virtual, através de um ambiente de imagens e dados geológicos, químicos e paragêneses 2 , que ultrapassa o espaço físico da sala de aula.

1 Lei Ordinária Estadual 14.708/2015 - publicada no DOE n. ${ }^{\circ}$ 134, de 16 de julho de 2015.

22 É o conjunto de minerais existentes em rochas ígneas, metamórficas e minérios, e que se formaram nas mesmas condições termodinâmicas de pressão, temperatura e pressão de voláteis (FERREIRA, 1980). 
No corrente ano, o Projeto foi agraciado com duas bolsas: uma do Programa de Desenvolvimento Acadêmico (Edital 02/2016-PDA-Unipampa) e outra da Pró-Reitoria de Extensão da Unipampa (Edital no 42/2016-ProFext) para alunos de graduaçáo. Ainda foi obtido financiamento para as despesas de campanhas de campo no Edital ProFext/2016.

As visitas nas escolas contam com apresentaçóes dinâmicas, de acordo com a faixa etária, envolvendo acontecimentos geológicos locais, regionais e globais. Neste contexto, são apresentados estudos e informaçóes geológicas, de modo didático, como por exemplo: a divisão do planeta Terra em núcleo, manto e crosta, rochas e minerais e os recursos extraídos na regiấo, vinculando com o dia a dia das crianças. Assim, facilita-se a visão através de maquetes realistas e interativas, como a construçáo da estrutura interna do planeta Terra e vulcóes que entram em erupção.

Isto auxilia na construçáo do pensamento científico na medida em que a criança transforma a informação abstrata em um material palpável. A propagação destes conhecimentos geológicos ultrapassa o meio cientifico e acadêmico. A comunidade local compreende a importância do estudo e preservação da área, bem como desperta o interesse dos jovens envolvidos.

\section{Geologia e inclusão social}

A Geologia é atualmente considerada como um dos fatores mais influentes no desenvolvimento humano, sendo considerada por alguns como determinante da evolução de uma sociedade (MATA-PERELLÓ et al., 2012). O estudo da Geologia deve direcionar esforços no sentido de dar respostas aos desafios que surgem como resultado do crescimento de zonas urbanas, o que gera uma influência direta sobre o bem-estar da sociedade. Da mesma forma, os problemas ambientais estâo intimamente ligados com o aumento da industrialização, sendo que estes parecem estar estreitamente relacionados com o crescimento da população humana. Em Caçapava do Sul, a população aumentou

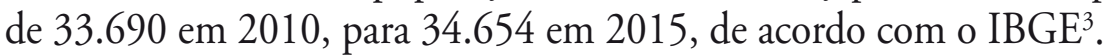

É necessário colocar em prática todos os conceitos e métodos geológicos e ambientais, especificamente no que se refere aos aspectos que têm uma influência sobre a sociedade: os recursos geológicos e os riscos geológicos. Também é necessário ligar a sociologia e a geologia, a fim de prever e reduzir os efeitos mais negativos e limitantes do ambiente geológico no que diz respeito à sociedade, ou seja, a falta de recursos geológicos nos países em desenvolvimento e a percepçáo de risco geológico.

Com o propósito de levar a geologia aos mais diferentes lugares, o Projeto desenvolveu um website (http://porteiras.unipampa.edu.br/MVGP). O site (Figura 1) conta com um catálogo online de rochas e minerais, das mais diferentes localidades do mundo; o catálogo está constantemente sendo atualizado e, consequentemente, são disponibilizadas novas imagens. Todo o material do catálogo é devidamente classificado e descrito de forma didática, porém, sem perder o caráter técnico, para que, assim, tanto estudantes de geologia como pessoas leigas no assunto possam sentir-se atraídas pela geologia. 


\section{Figura 1: Rochas ígneas vulcânicas do acervo de rochas do Museu Virtual Geológico do Pampa}

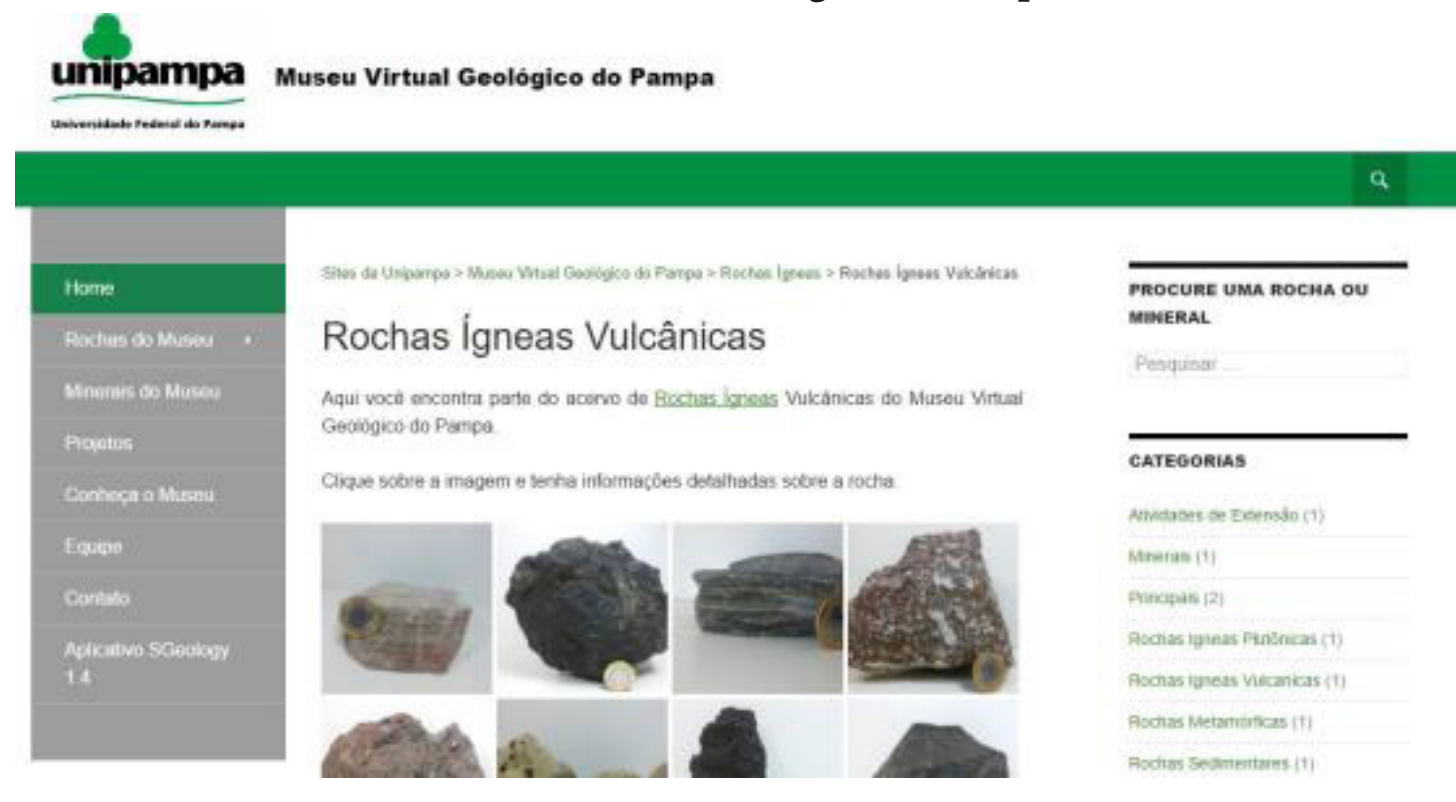

Fonte: Disponível em: http://porteiras.unipampa.edu.br/MVGP

Neste sentido, sendo a geologia uma área de caráter multidisciplinar, buscou-se integrar esta multidisciplinariedade com açôes envolvendo a comunidade. Tendo em vista que os processos geológicos estão presentes em todos os lugares e têm influência direta na sociedade, busca-se levar o conhecimento de como esses processos ocorreram ao maior número de indivíduos. E para que seja possível alcançar as pessoas da comunidade, que náo estáo ligadas diretamente à universidade, implementam-se as açôes de extensão.

\section{A importância das açóes de extensáo}

O anseio de levar para fora da universidade o que está sendo produzido dentro dela é o que caracteriza as açóes de extensão universitária. Entende-se a geologia também como uma ação social que integra o ambiente geológico e o desenvolvimento social, especialmente a influência de recursos geológicos e riscos sobre a gestáo territorial e social das zonas urbanas. Atualmente, os lucros e os impactos da exploração de recursos geológicos e os efeitos dos riscos geológicos não dependem de sua natureza geológica. Eles sáo controlados por fatores socioeconômicos e territoriais. Assim, a integraçáo da classificação geológica e a comunidade local é essencial. Levar aos mais diferentes indivíduos todo o conhecimento produzido dentro da universidade é o principal objetivo da extensão, como escreveu Villar (2011, p. 51): "Extensão universitária se forma influenciada pelos ideais das universidades populares de levar o conhecimento ao povo, mas se consolida a partir da prática da universidade da multiversidade ${ }^{4 "}$.

A universidade, além do compromisso com a educação e a pesquisa, tem uma função social; articular e traçar estratégias para integrar o ensino e a pesquisa juntamente com a extensão a favor da comunidade local onde ela está inserida é de extrema importância.

4 Kerr (1982) "é uma metrópole de infinita variedade. Alguns nela se perdem; outros atingem o máximo dentro dela; a maioria modela-se à feição de uma de suas múltiplas subculturas". 
Desenvolver açóes de extensáo que condizem com a realidade da determinada comunidade é um dever social da universidade.

Partindo destes pressupostos, desenvolveu-se, juntamente com crianças e adolescentes de escolas de nível fundamental do município de Caçapava do Sul, açóes voltadas à prática de geociências, estimulando nelas a busca pelo conhecimento. De forma prática, os trabalhos foram voltados à realidade socioeconômica e cultural do município, onde grande parte da economia está voltada para o setor de prospecção mineral. Neste sentido, objetivou-se estimular as crianças e os adolescentes a práticas voltadas às Ciências da Terra. A seguir, são descritas algumas práticas estimuladas e realizadas neste Projeto.

\section{Estimulando a aprendizagem a partir de açóes práticas e observatórias}

O uso dos estímulos para o desenvolvimento de crianças é fundamental, por isso, o Projeto prevê açóes de cunho prático e, ao mesmo tempo, educativo. Existem diversos tipos de estímulos, como por exemplo sensoriais, físicos e cognitivos, cada um com a sua particularidade.

O estímulo físico envolve atividades de movimentação e coordenação, ao passo que o sensorial procura desenvolver os sentidos, isto é, o tato, olfato, audiçáa, dentre outros. Já o estímulo cognitivo procura estimular a atenção, a criatividade, curiosidade e observação. E é neste ponto que o Projeto pretende atuar: através de estímulos à criatividade, curiosidade e observação.

É unânime o consenso de que a criança necessita de estímulos visuais para a melhor compreensão de tudo aquilo que está à sua volta, escreveu Freire:

[...] não se passa do mundo concreto para a representação mental senão por intermédio da açáo corporal. A criança transforma em símbolos aquilo que pode explorar corporalmente: o que ela vê, cheira, pega, chuta aquilo de que corre e assim por diante (FREIRE, 1978 apud SCHIAVO et al., 2007, p. 6).

Por isso, buscou-se aliar a teoria e a prática de forma lúdica e didática, para uma melhor compreensão dos eventos geológicos que ocorrem no planeta. Reginaldo, Sheid e Güllich (2012 p. 2) destacam, sobre o ensino de ciências, "a dificuldade do aluno em relacionar a teoria desenvolvida em sala com a realidade a sua volta [...]". Tendo isto em vista, a seguir é discutida a metodologia utilizada para o desenvolvimento das açôes didático-pedagógicas com as crianças.

\section{Metodologia}

Fazer uso de uma metodologia voltada para a prática, isto é, com estímulos aos sentidos, o toque, a visualizaçáo, é de fundamental importância, principalmente quando se trata de crianças e adolescentes. Por essa razão, utilizou-se uma metodologia em que o foco era a construçáo e a experimentação.

Estimular o toque e a visualizaçáo das crianças é crucial, utilizar os diferentes sentidos durante a formação do educando é primordial. Tendo em vista que, além de ser fundamental utilizá-los, o processo de ensino-aprendizagem torna-se muito mais lúdico e 
elucidativo. Pensando nisto, a equipe do Projeto elaborou atividades lúdico-pedagógicas a serem desenvolvidas com as crianças.

Para a realizaçáo do presente Projeto e para facilitar o aprendizado dos alunos das escolas participantes, estudou-se a melhor forma de fazer com que as visitas nas escolas fossem uma experiência diferente para os alunos. Ao se promover atividades interativas, planejou-se a criaçáo de uma réplica do globo terrestre, em que os estudantes poderiam ver as divisóes das camadas internas da Terra (crosta, manto e núcleo), expressa de forma didática, podendo ser manuseada e montada/desmontada pelos próprios alunos.

No processo de confecção do globo, utilizou-se uma bola de vinil, a qual foi revestida com papel machê, conforme mostra a Figura 2. Após o término deste processo, que cerca de duas semanas até a secagem completa do material, o globo foi pintado e cortado (Figura 3), para que entáo fosse possível montar as estruturas internas, representando, assim, as camadas do interior da crosta terrestre.

Figura 2: Início da construçáo do globo terrestre, maquete interativa, com papel machê, no laboratório da UNIPAMPA

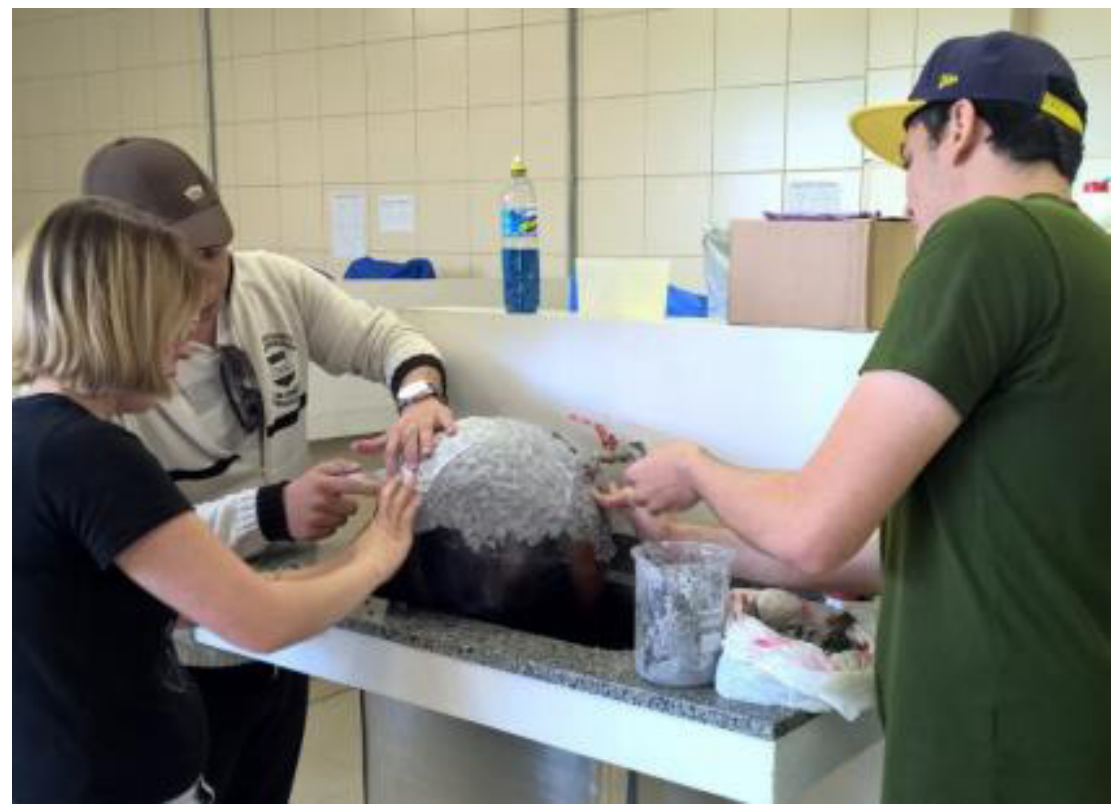

Figura 3: Processo de finalizaçáo da construção do globo terrestre esquemático

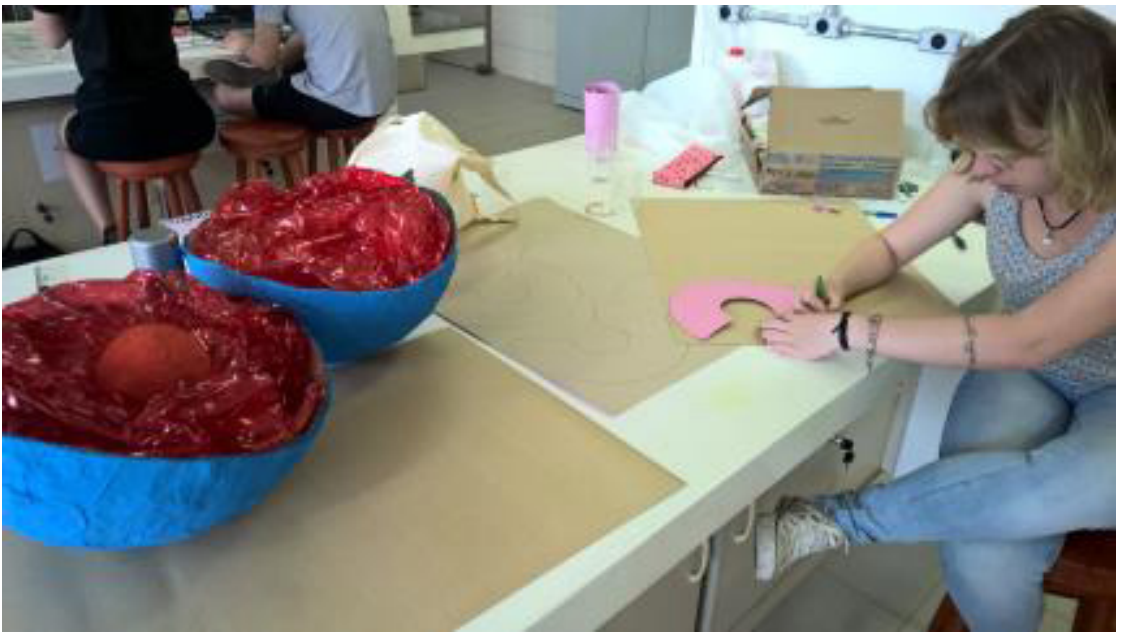




\section{Resultados}

A experiência ocorreu em uma escola com alunos do quinto ano. Iniciou-se a palestra com questôes sobre o surgimento do Universo e do planeta Terra. Para explicar a Teoria do Big Bang (Teoria apresentada por George Gamow, em 1948, e dominante entre os cientistas), foi exemplificado que o Universo surgiu após uma grande explosão, e as partículas provenientes desta explosão deram origem ao Universo. Sobre a teoria, Cordani (2000, p. 4) sustenta que, por meio dos conhecimentos já existentes acerca da matéria, energia, radiaçóes e partículas elementares, e apoiando-se sobre a física teórica e também modelagens e simulaçóes, cientistas reconstituíram com grande precisão as etapas sucessivas à Grande Explosão.

Como atividade lúdico-pedagógica, os próprios alunos foram voluntários em uma atividade em que simulavam as partículas liberadas pela grande explosão, que, ao se unirem com passar do tempo, formavam estrelas e planetas do nosso sistema solar.

Após a pequena brincadeira, foi explicado sobre a formação e evolução do planeta Terra ao longo dos anos, dando-se enfoque sobre o Tempo Geológico. Muitas pessoas têm certa dificuldade de compreender completamente este Tempo, por isso a necessidade de se trabalhar acerca do tema, para se compreenderem as divisóes do tempo geológico em éons, eras, períodos e épocas.

Os geólogos diferenciam-se dos demais cientistas devido à forma como encaram o tempo. Os físicos e os químicos estudam processos que duram somente as últimas fraçôes de um segundo: a separação de um núcleo atômico, uma rápida reação química. Outros cientistas efetuam experimentos que duram minutos, horas ou dias. Os geólogos, ao contrário disso, tratam de processos da Terra que se desenvolvem numa grande multiplicidade de diferentes duraçóes de tempo. Desde tremores de um terremoto, que duram segundos ou minutos, até o soerguimento de montanhas, que leva vários milhôes de anos para acontecer. (PRESS, 2006, p. 247-248)

Também foi narrado sobre a estrutura interna do planeta, utilizando-se o globo que foi construído, através de diálogos e explanaçôes com as crianças sobre cada uma das camadas e a estrutura interna da Terra (Figura 4). Após a interlocução, muitas questōes foram levantadas pelos alunos, a exemplo de uma pergunta feita por um dos alunos: "Se o núcleo do nosso planeta é táo quente, por que existe neve na superfície e como não morremos?”. Então, foi explicado que o calor do núcleo se dissipa conforme se afasta do centro da Terra e que a crosta, camada mais externa da Terra, serve como uma barragem que impede que o calor interno a ultrapasse, do mesmo modo que impede que o frio externo penetre, e ainda que as condições climáticas estão ligadas ao movimento de rotaçấo do planeta. Este foi apenas um exemplo dentre os diversos questionamentos e dúvidas que surgiram. 
Figura 4: Palestra sobre a origem do universo e planeta Terra na escola do município

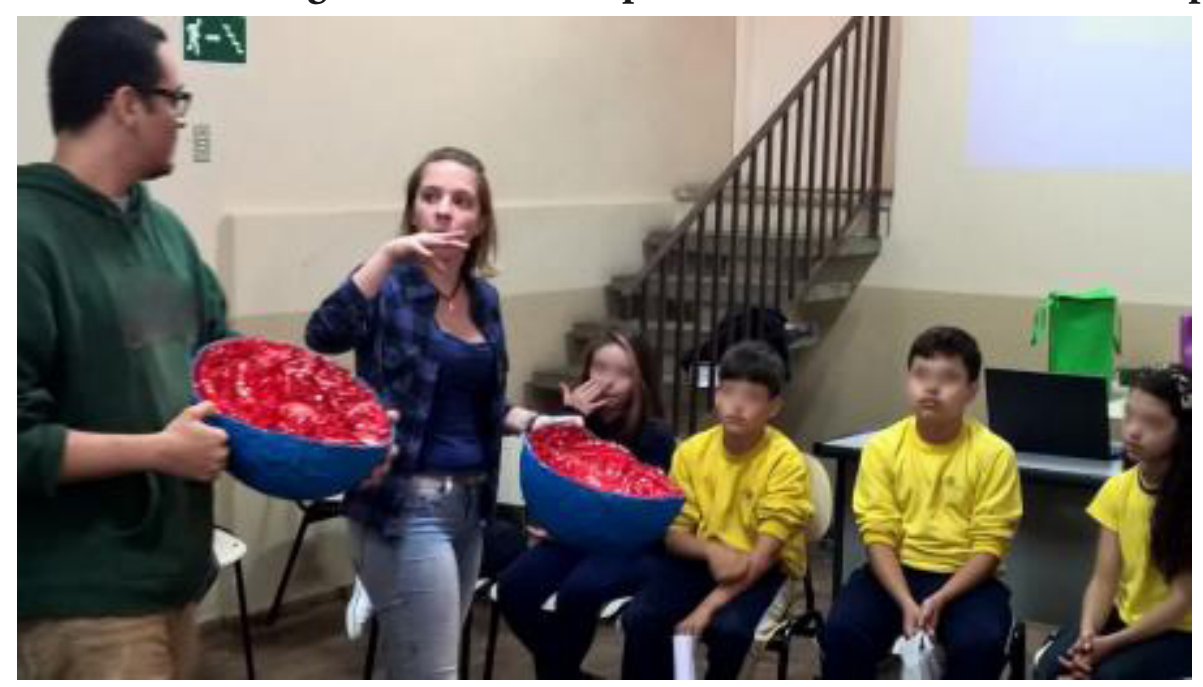

Com a ajuda de graduandos do curso de Geologia e Geofísica, que auxiliam no Laboratório de Mineralogia e Petrografia da Universidade, foram levadas amostras de rochas que são encontradas na região e explicou-se, de forma didática, os diferentes processos de formação das rochas, bem como os seus ciclos. Foram levadas lupas de mão (do tipo lupa de campo), para que eles pudessem ver em detalhes as rochas e seus minerais constituintes. Na Figura 5 é possível observar uma aluna utilizando a lupa em uma das amostras, enquanto é instruída.

\section{Figura 5: Aluna da escola do município observando} amostra de rocha, enquanto é instruída

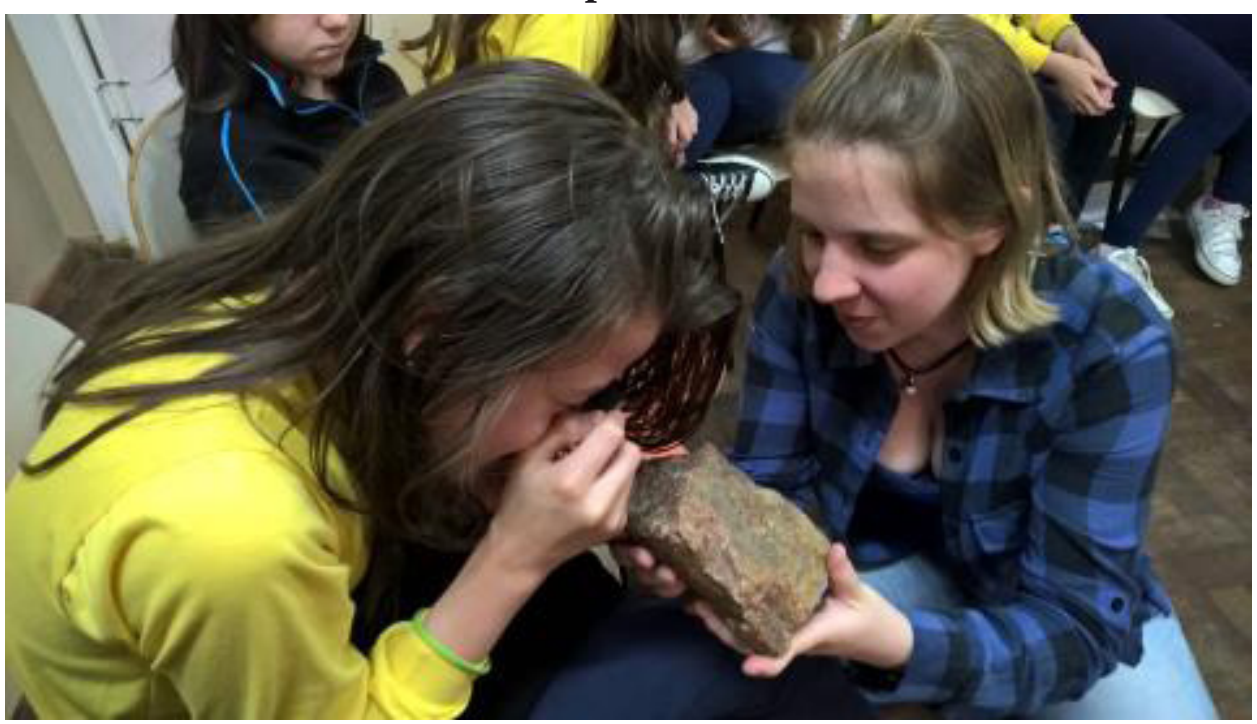

\section{Conclusão}

Após a ação do Projeto Virtual Geológico do Pampa, percebeu-se que estimular e desenvolver o senso de experimentação e observação em crianças se mostrou uma prática muito importante, principalmente na área de Geociências. Percebe-se que, a partir do momento em que o estudo teórico torna-se palpável para a criança, a mesma sente-se 
motivada a interagir com aquilo que está sendo proposto. No caso do Projeto, valer-se de intervençôes como a simulaçáo dos alunos, onde eles eram as partículas da Grande Explosão, tornou o processo de aprendizagem muito mais lúdico e didático para esses alunos.

Neste sentido, o Projeto vem atuando com muitas ideias e perspectivas a serem desenvolvidas. A atuaçáo dos bolsistas nessas experiências iniciais modificou as formas de lidar com os conteúdos disciplinares da Universidade e amplificou o pensamento do quão importante são as atividades de ensino e extensão voltadas para o público infanto-juvenil. Foi possível perceber que o processo de ensino-aprendizagem vai muito além da teoria. Assim, é indispensável que existam, aliados à teoria, a prática, a visualizaçáo e o estímulo aos sentidos da criança.

Constatou-se, após a atividade, que a capacidade de aprendizagem do educando é muito maior quando ele sente prazer naquilo que está fazendo e/ou observando. A iniciação científica de crianças e adolescentes é primordial para que possam não só conhecer novas áreas de estudos, mas também ter um conhecimento, ainda que iniciante, sobre a gigantesca e diversificada área do conhecimento chamada Geociência.

\section{Referências}

BORBA, A.W. Proposta de uma (geo)identidade visual para Caçapava do Sul, "Capital Gaúcha da Geodiversidade". Geographia Meridionalis, Pelotas, v. 1, n. 2 jul-dez. 2015. Disponível em: <https://periodicos.ufpel.edu.br/ojs2/index.php/Geographis/article/ view/6981/4927>. Acesso em: 02 mai. 2016.

CORDANI, G.U. O planeta Terra e suas origens. In: TEIXEIRA; TOLEDO; FAIRCHILD; TAIOLI (Org.). Decifrando a Terra. 2. ed. São Paulo: Companhia Editora Nacional, 2009, p. 1-26.

FERREIRA, J.B. Dicionário de Geociências. São Paulo: Madras, 1980.

REVISTA BRASILEIRA DE GEOGRAFIA. Rio de Janeiro: IBGE. População de Caçapava do Sul, do IBGE Cidades. Disponível em: < http://cod.ibge.gov.br/464> Acesso em: 12 abr. 2016.

PRESS, F.; SIEVER, R.; GROTZINGER, J.; JORDAN, T.H. Registro das Rochas e Escala do Tempo Geológico In: GROTZINGER; JORDAN (Org.). Para Entender a Terra. 4. ed. Porto Alegre: Bookman, 2006, p. 247-248.

REGINALDO, C.C.; SHEID, N.J.; GÜLLICH, R.I.C 0 ensino de ciências e a experimentação. In: SEMINÁRIO DE PESQUISA EM EDUCAÇÃO DA REGIÃO SUL, 9., 2012, Caxias do Sul. Anais... Caxias do Sul, 2012. 1 CD-ROM.

RIO GRANDE DO SUL (Estado). Lei Ordinária Estadual n 14.708, de 15 de julho de 2015. Assembléia Legislativa do estado do Rio Grande do Sul, Porto Alegre, RS, DOE n. ${ }^{\circ} 134$, de 16 de julho de 2015.

MATA-PERELLÓ, J.M.; MATA-LLEONART, R.; VINTRÓ-SÁNCHEZ, C.; RESTREPO-MARTÍNEZ, C. Social Geology: a new perspective on Geology. Dyna, Colômbia, v. 79, n. 171, p. 158-166, 2012. 
SCHIAVO, A. A. N.; RIBÓ, C. M. E. Estimulando todos os sentidos de $\mathbf{0}$ a $\mathbf{6}$ anos. In: SEMINÁRIO DO CONGRESSO DE LEITURA DO BRASIL, 16., 2007, Campinas. Anais... Campinas, 2007. 1 CD-ROM.

VILLAR, A. E. V. Nova concepção de extensão universitária no Brasil. 2011. 131f. Dissertação (Mestrado em Serviço Social) - Universidade Federal do Rio Grande do Norte, Natal, 2011. 